\title{
Ecological insights from three decades of animal movement tracking across a changing Arctic
}

Sarah C. Davidson ${ }^{1,2,3}$, Gil Bohrer ${ }^{1 *}$. Eliezer Gurarie ${ }^{4,5}$, Scott LaPoint ${ }^{2,6,7}$, Peter J. Mahoney ${ }^{8}$. Natalie T. Boelman ${ }^{7}$, Jan U. H. Eitel ${ }^{9}$, Laura R. Prugh ${ }^{8}$, Lee A. Vierling ${ }^{9}$, Jyoti Jennewein ${ }^{9}$, Emma Grier ${ }^{4}$, Ophélie Couriot ${ }^{4,10}$, Allicia P. Kelly ${ }^{11}$, Arjan J. H. Meddens ${ }^{12}$, Ruth Y. Oliver ${ }^{7,13,14}$, Roland Kays ${ }^{15}$, Martin Wikelski ${ }^{2,3}$, Tomas Aarvak $^{16}$, Joshua T. Ackerman ${ }^{17}$, José A. Alves ${ }^{18,19}$, Erin Bayne ${ }^{20}$, Bryan Bedrosian ${ }^{21}$, Jerrold L. Belant ${ }^{22}$, Andrew M. Berdahl ${ }^{23}$. Alicia M. Berlin ${ }^{24}$, Dominique Berteaux $x^{25}$, Joël Bêty ${ }^{25}$, Dmitrijs Boiko ${ }^{26,27,28}$, Travis L. Booms ${ }^{29}$, Bridget L. Borg ${ }^{30}$, Stan Boutin ${ }^{20}$, W. Sean Boyd ${ }^{31}$, Kane Brides ${ }^{32}$, Stephen Brown ${ }^{33}$, Victor N. Bulyuk ${ }^{34}$, Kurt K. Burnham ${ }^{35}$, David Cabot ${ }^{36}$, Michael Casazza ${ }^{17}$, Katherine Christie ${ }^{37}$, Erica H. Craig ${ }^{38}$, Shanti E. Davis ${ }^{39}$, Tracy Davison ${ }^{40}$, Dominic Demma ${ }^{41}$, Christopher R. DeSorbo ${ }^{42}$ Andrew Dixon ${ }^{43}$, Robert Domenech ${ }^{44}$, Götz Eichhorn ${ }^{45,46}$, Kyle Elliott ${ }^{47}$, Joseph R. Evenson ${ }^{48}$, Klaus-Michael Exo ${ }^{49}$, Steven H. Ferguson ${ }^{50}$, Wolfgang Fiedler ${ }^{2,3}$, Aaron Fisk ${ }^{51}$, Jérôme Fort ${ }^{52}$, Alastair Franke ${ }^{20.53}$, Mark R. Fuller ${ }^{54}$, Stefan Garthe $e^{55}$, Gilles Gauthier ${ }^{56}$, Grant Gilchrist ${ }^{57}$, Petr Glazov ${ }^{58}$, Carrie E. Gray ${ }^{59}$, David Grémillet ${ }^{60,61}$, Larry Griffin ${ }^{32}$, Michael T. Hallworth ${ }^{62,63}$, Autumn-Lynn Harrison ${ }^{62}$, Holly L. Hennin ${ }^{31,64}$, J. Mark Hipfner ${ }^{65}$, James Hodson ${ }^{66}$, James A. Johnson ${ }^{67}$, Kyle Joly ${ }^{68}$, Kimberly Jones ${ }^{41}$, Todd E. Katzner ${ }^{69}$, Jeff W. Kidd ${ }^{70}$, Elly C. Knight ${ }^{20}$, Michael N. Kochert ${ }^{69}$, Andrea Kölzsch ${ }^{2,3,7}$, Helmut Kruckenberg ${ }^{71}$, Benjamin J. Lagassé ${ }^{72}$. Sandra Lai ${ }^{25}$, Jean-François Lamarre ${ }^{73}$, Richard B. Lanctot ${ }^{67}$, Nicholas C. Larter ${ }^{74}$, A. David M. Latham ${ }^{20,75}$, Christopher J. Latty ${ }^{76}$, James P. Lawler ${ }^{7}$, Don-Jean Léandri-Breton ${ }^{25}$, Hansoo Lee ${ }^{78}$, Stephen B. Lewis ${ }^{79}$, Oliver P. Love ${ }^{64}$, Jesper Madsen ${ }^{80}$, Mark Maftei ${ }^{39}$, Mark L. Mallory ${ }^{81}$, Buck Mangipane ${ }^{82}$, Mikhail Y. Markovets ${ }^{34}$, Peter P. Marra ${ }^{83}$, Rebecca McGuire ${ }^{84}$, Carol L. McIntyre ${ }^{30}$, Emily A. McKinnon ${ }^{85}$, Tricia A. Miller ${ }^{86,87}$, Sander Moonen ${ }^{49}$, Tong Mu ${ }^{88}$, Gerhard J. D. M. Müskens ${ }^{89}$, Janet $\mathrm{Ng}^{20}$, Kerry L. Nicholson ${ }^{29}$, Ingar Jostein Øien ${ }^{16}$, Cory Overton ${ }^{17}$, Patricia A. Owen ${ }^{30}$, Allison Patterson ${ }^{47}$, Aevar Petersen ${ }^{90}$, Ivan Pokrovsky ${ }^{291,92}$, Luke L. Powell ${ }^{62,93,94}$, Rui Prieto ${ }^{95}$, Petra Quillfeldt ${ }^{96}$, Jennie Rausch ${ }^{97}$, Kelsey Russell ${ }^{98}$, Sarah T. Saalfeld ${ }^{67}$, Hans Schekkerman ${ }^{99}$, Joel A. Schmutz ${ }^{100}$, Philipp Schwemmer ${ }^{55}$, Dale R. Seip ${ }^{101}$, Adam Shreading ${ }^{44}$, Mónica A. Silva ${ }^{95,102}$, Brian W. Smith ${ }^{103}$, Fletcher Smith ${ }^{104,105}$, Jeff P. Smith ${ }^{106,107}$, Katherine R. S. Snell ${ }^{2,108}$, Aleksandr Sokolov ${ }^{92}$, Vasiliy Sokolov ${ }^{109}$, Diana V Solovyeva ${ }^{91}$, Mathew S. Sorum ${ }^{110}$, Grigori Tertitski ${ }^{58}$, J. F. Therrien ${ }^{56,111}$, Kasper Thorup ${ }^{108}$, T. Lee Tibbitts ${ }^{100}$ Ingrid Tulp ${ }^{112}$, Brian D. Uher-Koch ${ }^{100}$, Rob S. A. van Bemmelen ${ }^{112,113}$, Steven Van Wilgenburg ${ }^{114}$, Andrew L. Von Duyke ${ }^{115}$, Jesse L. Watson ${ }^{20}$, Bryan D. Watts ${ }^{104}$, Judy A. Williams ${ }^{66}$, Matthew T. Wilson ${ }^{48}$, James R. Wright ${ }^{116}$, Michael A. Yates ${ }^{117}$, David J. Yurkowski ${ }^{50,85}$, Ramûnas Žydelis ${ }^{118}$, Mark Hebblewhite ${ }^{5}$

The Arctic is entering a new ecological state, with alarming consequences for humanity. Animal-borne sensors offer a window into these changes. Although substantial animal tracking data from the Arctic and subarctic exist, most are difficult to discover and access. Here, we present the new Arctic Animal Movement Archive (AAMA), a growing collection of more than 200 standardized terrestrial and marine animal tracking studies from 1991 to the present. The AAMA supports public data discovery, preserves fundamental baseline data for the future, and facilitates efficient, collaborative data analysis. With AAMA-based case studies, we document climatic influences on the migration phenology of eagles, geographic differences in the adaptive response of caribou reproductive phenology to climate change, and species-specific changes in terrestrial mammal movement rates in response to increasing temperature.

he Arctic and adjacent regions are experiencing the most rapid climate and environmental changes on Earth, caused primarily by anthropogenic greenhouse gas emissions $(I)$. Notable trends include warming winter temperatures, ice loss, and earlier spring snowmelt. These changes profoundly affect conditions experienced by animals, including food availability, interspecific Author affiliations are listed at the end of this paper. *Corresponding author. Email: bohrer.17@osu.edu competition, predation, and increased human disturbances (2). Impacts of climate change on Arctic vertebrates include rapid poleward range shifts $(3,4)$; phenological trophic mismatches (5); and changes in migration (6), foraging, and predator-prey dynamics (7). Because rapid environmental change in the Arctic challenges the ability of the region's fauna to adapt, a primary response will likely occur through phenotypic plasticity in the patterns, locations, and timing of their movements
(2). Documenting and understanding these changes requires multidecadal, pan-Arctic data at multiple trophic levels.

We demonstrate the ecological utility of the Arctic Animal Movement Archive (AAMA), an active, collaborative collection of animal tracking datasets (supplementary materials). Marine ecology archives, such as IOOS-ATN, IMOS, OBIS-SEAMAP, and RAATD (8), provide insight regarding space use, movement, and connectivity (9-11). Terrestrial animal movement archives are rare and tend to have a regional or taxonomic focus (12). AAMA is the first Arctic-focused archive with both terrestrial and marine data and is hosted on the global Movebank database. The geographic scope of the AAMA (Fig. 1) includes the Arctic, Arctic marine, and subarctic "boreal forests/ taiga" regions defined elsewhere $(13,14)$ (see also supplementary materials). Currently, the archive contains more than $15,000,000$ occurrences of 8000 individuals representing 86 species, from 1991 to the present (figs. S1 and S2 and tables S1 to S4). Combining data from multiple AAMA studies, we show evidence of (i) climate drivers of golden eagle migration phenology, (ii) climate adaptation of parturition by caribou, and (iii) consequences of increased temperature and precipitation on movements of mammalian predators and herbivores.

Behavioral flexibility enables migrants to optimize energy expenditure during migration and adjust arrival at summering grounds $(15,16)$. We used tracking data from 103 individuals during 1993 to 2017 [supplementary materials (case study 1) and table S5] to examine arrival timing to breeding grounds of northwardmigrating golden eagles ("summering"), modeling it with predictors for age, sex, summering onset latitude, year, and the preceding winter's mean Pacific decadal oscillation index (PDO).

Mean summering date changed slowly over 25 years ( -0.5 days/year). The long-term trend differed among age classes, with adults arriving earliest, then subadults, and then juveniles, and it was influenced by winter climate (PDO) (Fig. 2 and tables S8 and S9). Eagles of all age classes began summering later at northern latitudes (1.08 days/degree). The significant interaction of year and previous "warm-phase" PDO explains earlier summering dates for subadults and juveniles, highlighting their known responsiveness to environmental conditions (16). These warm-phase winters cause a warmer and drier climate with reduced snowpack and an earlier snow-free date. Earlier adult arrival to summering grounds should result from selection and competition for territories, yet local climatic variables affect eagle condition before, and energy expenditure during, northward migration (16). For subadults sampled after 2011, the direct effect of $\mathrm{PDO}$ is significant $(-8.27$ days), whereas the full subadult dataset does not show a 
significant effect of winter PDO (Fig. 2). This period-related difference in inference of climatic drivers highlights the importance of compiling long-term, multigenerational observations. Given the importance of the winter PDO and known impacts of global climate change, golden eagles could face age-specific challenges during migration and at their warming Arctic summering grounds.

The timing of parturition is a key to the demography of wildlife populations and can be an adaptive response to climate shifts (17) For many mammals, the period from late pregnancy through weaning has the highest energetic demands and thus is timed to occur when vegetation productivity is highest (18). Caribou occur in five different ecotypes (Fig. 3) across boreal and Arctic North America and are facing global declines (19). On the basis of data from 917 individuals during 2000 to 2017 in northern Canada, we used characteristic patterns of low movement during the calving season to estimate 1630 parturition dates in five populations of barren-ground, northern and southern boreal woodland, and northern and southern mountain woodland caribou [supplementary materials (case study 2 ) and table S6].

We found differences in parturition timing and trends among the five populations. The southern and northern boreal populations calved earliest, followed by northern and southern mountain populations (table S10). Barren-ground caribou calved later despite occupying a similar latitudinal range as the northern boreal caribou (Fig. 3). Most importantly, barren-ground and northern woodland caribou, but not southern woodland caribou, exhibited significant trends toward earlier parturition [0.4 to 1.1 days/ year (table S10)]. This is the first continentalscale retrospective evidence of potential adaptive responses to climate trends by caribou.

Animals conserve energy by modifying their behavior in response to weather conditions, with important implications for individual fitness and species resilience under climate change (20). We tested for effects of temperature and precipitation on seasonal movement rates (in meters per minute) using records from 1720 individuals of two herbivore and three predator species (black bear, grizzly bear, caribou, moose, and wolf) during 1998 to 2019 [supplementary materials (case study 3 ) and table S7]. We predicted that winter movement rates would decline relative to summer, when energetic costs of self-maintenance would be highest. Rate would also decline within seasons, during weather conditions that increase the energetic cost of movement (e.g., snow that increases energy requirements for movement or higher ambient temperatures during the summer that accelerate metabolism).

All species exhibited lower movement rates during winter relative to summer (Fig. 4). As

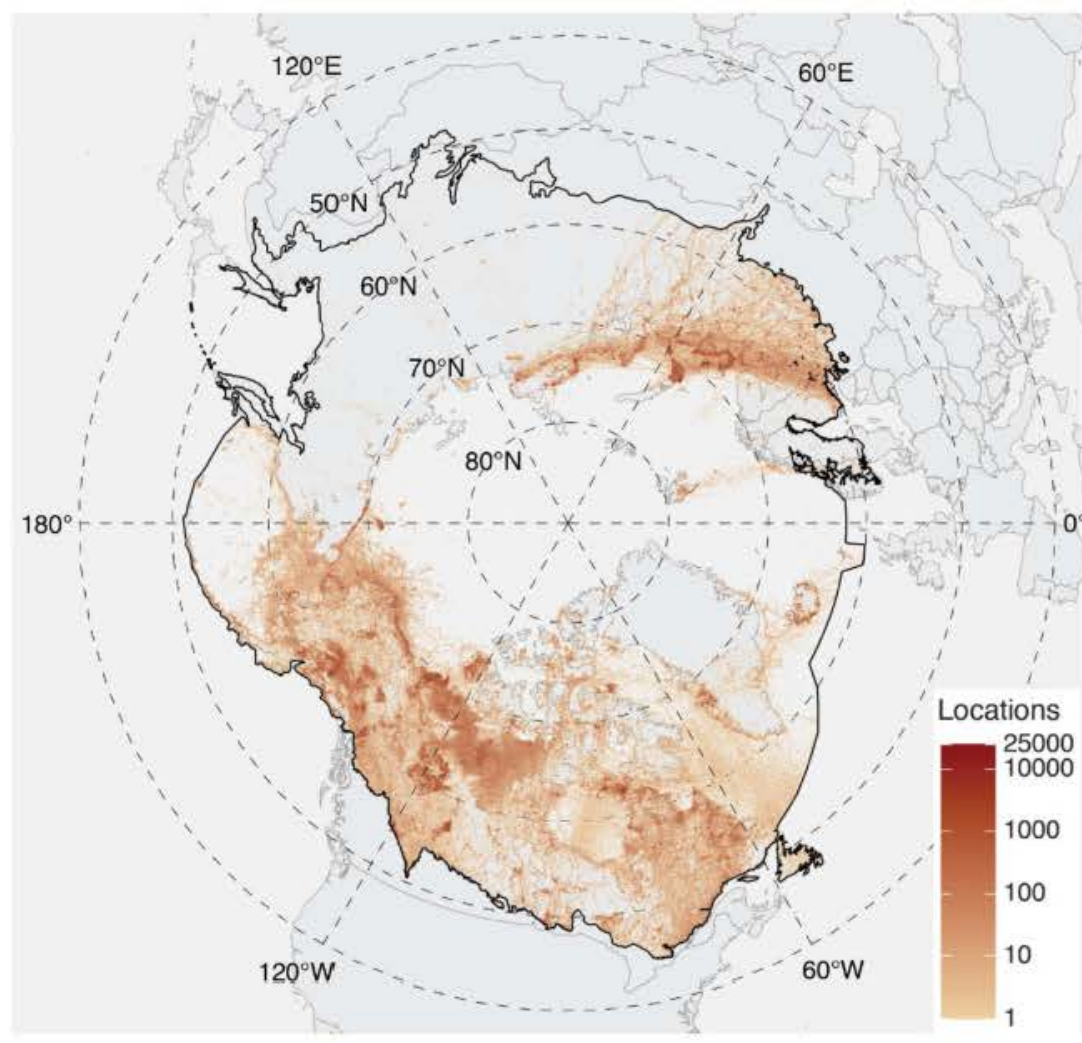

Fig. 1. Map of the AAMA boundary and data. Density of animal locations (number of observations per $\sim 100 \mathrm{~km}^{2}$ ) at logarithmic scale characterizes data availability, not animal density or utilization.

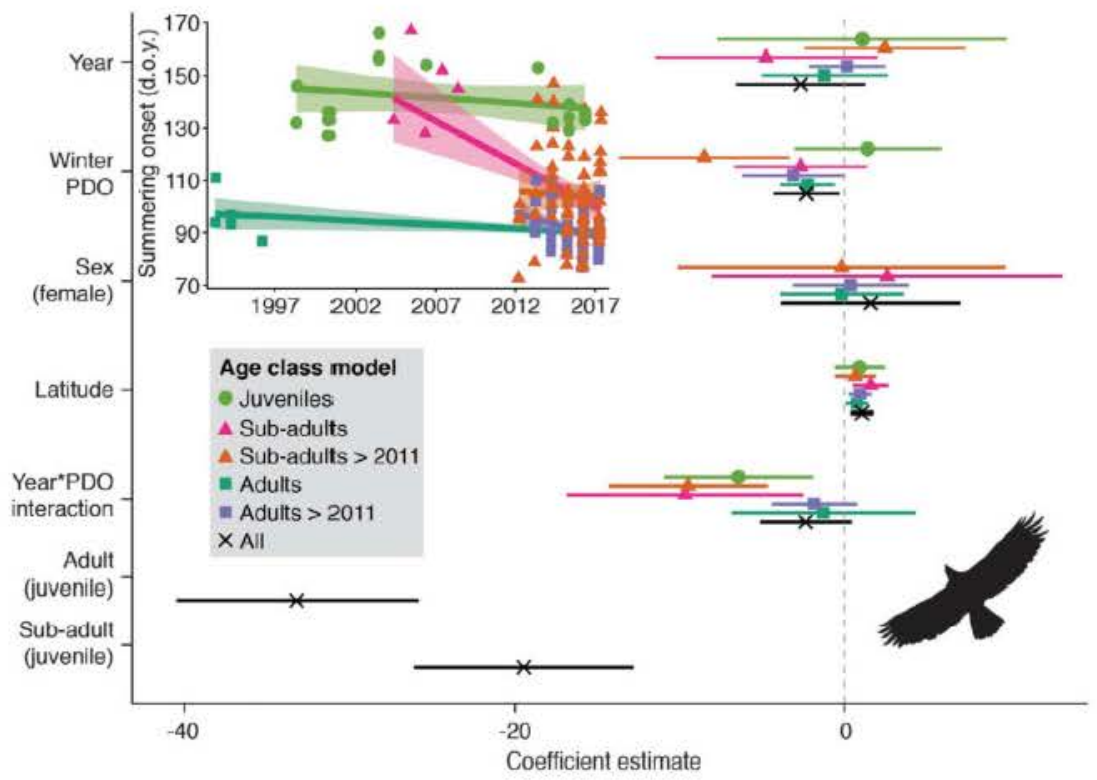

Fig. 2. Changes in the onset date of golden eagles' summering. Coefficient estimates $( \pm 95 \%$ confidence intervals) reflecting age-specific changes in response to year, previous winter PDO, sex (reference: females), latitude, interaction of year and PDO, and age class [reference: juveniles (tables S8 and S9)]. (Inset)

Time series of model-estimated summering. d.o.y., day of year. 


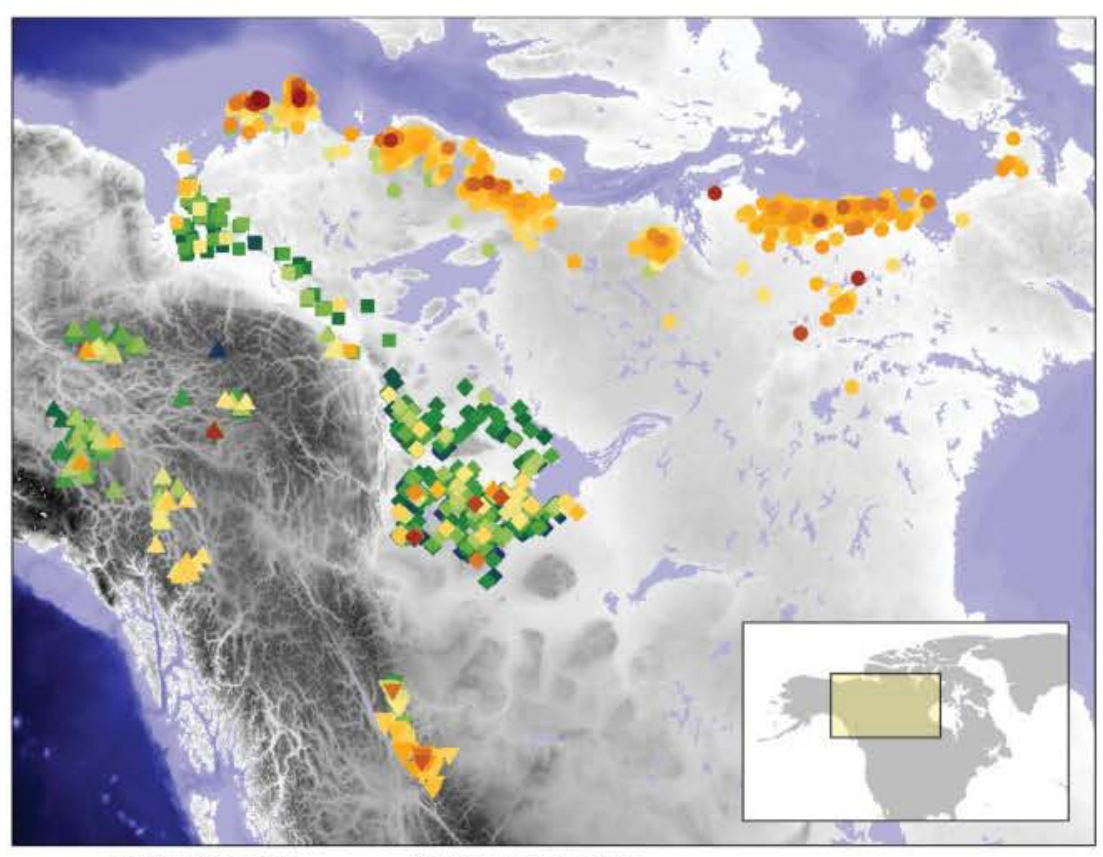

Parturition date

apr 30

May 15

May 30

in 14

- Jun 29

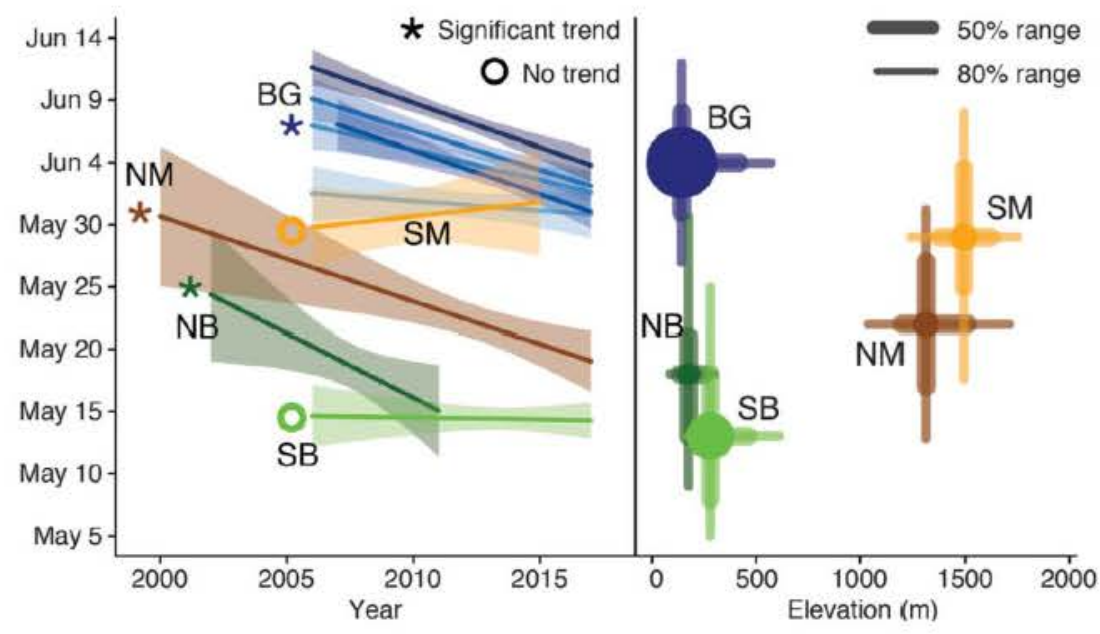

Fig. 3. Climate change adaptation of parturition times (PT) of caribou. (Top) PT by population. (Bottom left) PT trends by population, including five barren-ground subpopulations. (Bottom right) PT dates by elevation.

temperatures increased in summer, wolves and black bears slowed their movement rates, whereas moose increased their movement rates. In winter, only barren-ground caribou increased movement rates as temperature increased. Snow impeded wolves, boreal caribou, and moose,
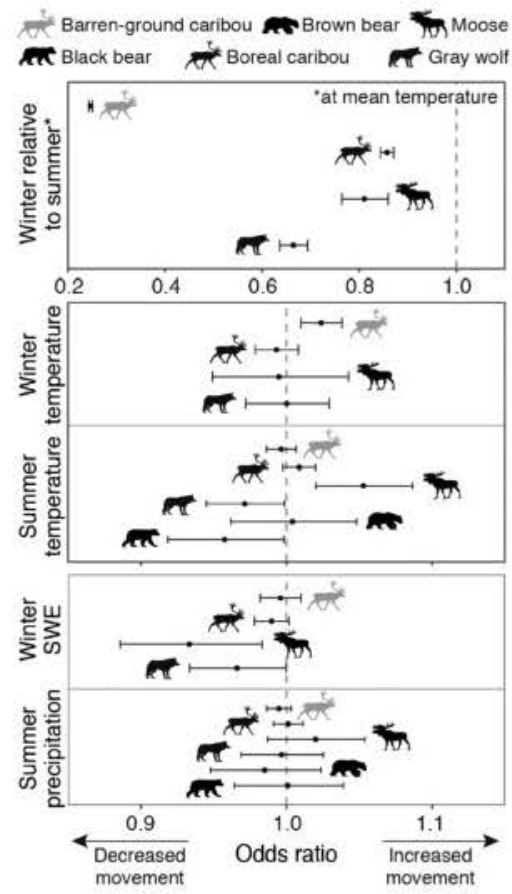

Fig. 4. Changes in species-specific movement rates in response to daily maximum temperature, summer precipitation, and winter snow-water equivalent (SWE). Odds ratios for continuous covariates represent the positive or negative change in movement rates per one unit change in temperature or precipitation. respectively. Ratios were identified as neutral if credible intervals overlapped with 1.0 .

expenditure, encounter rates, and foraging success with demographic implications for both predators and prey.

As we demonstrate, the AAMA provides a solution to Arctic data collection and sharing challenges. It serves as a critical baseline and resource to identify early signals of local or large-scale changes in animal distribution, movement responses, and adaptive traits. Continued shifts in phenology in the Arctic pose challenges to migratory species that encounter changing seasonal fluctuations along migration routes and at Arctic summering and southern wintering grounds (21). Key drivers of population responses, such as migration, parturition, and foraging movement, are undergoing rapid changes, suggesting that climate change is affecting animals in ways that will shape the future of the Arctic.

whereas all species were generally insensitive to summer precipitation. These patterns may reflect asynchronous responses to climate change within and across trophic levels. Climatedriven variation in animal activity is likely to affect species interactions, altering energy

\section{REFERENCES AND NOTES}

1. IPCC, "Climate change 2014: Synthesis report. Contribution of Working Groups I. II and III to the Fifth Assessment Report of the Intergovernmental Panel on Climate Change" (IPCC, 2015). 
2. O. Gilg et al.. Ann. N. Y. Acad. Sci. 1249, 166-190 (2012)

3. M. Fossheim et al., Nat. Clim. Chang, 5. 673-677 (2015)

4. I.C. Chen, J. K. Hill, R. Ohlemuller, D. B. Roy. C. D. Thomas. Science 333, 1024-1026 (2011).

5 S. T. Saalfeld, R. B. Lanctot, Ecol. Evol. 7. 10492-10502 (2017)

6. D. H. Ward et al., L. Avian Biol. 47, 197-207 (2016).

7. R. F. Rockwell, L. I, Gormezano, D. N. Koons, Olkos 120 696-709 (2011)

8. Y. Ropert-Coudert et al, Sci, Data 7.94 (2020)

9. M. A. Hindell et al, Nature 580, 87-92 (2020).

10. G. C. Hays et al., Trends Ecol. Evol 34, 459-473 (2019).

II. S. Brodie et at. Sci. Rep. 8. 3717 (2018)

12. F. Casnacci et al., Oikos 120. 1790-1802 (2011)

13. 1. L. Murray. L. Hacquebord, D. J. Gregor, H. Loeng, Eds. in "AMAP assessment report: Arctic pollution issues" (Arctic Monitoring and Assessment Programme. 1998). chap. 2, pp. 9-23.

14. The Nature Conservancy, tnc_terr_ecoregions (2009): hittp://maps.tnc.org/files/metadata/TerrEcos.xml

15. D. W. Winkler et al., Mov. Ecol. 2. 10 (2014)

16. T. A. Miller et at, ibis 158, 116-134 (2016)

17. T. Bonnet et al. PLOS Biol. 17. e3000493 (2019)

17. T. Bonnet et ail, PLOS Biol. 17. ejo00493 (2019). T. C. L. Edwards Jr, PLOS ONE 11 e0148780 (2016)

19 L. S. Vors, M. S. Boyce, Glob. Change Biol. 15. 2626-2633 (2009)

20. A. Clarke, K. P. P. Fraser, Funct. Ecol. 18, 243-251 (2004)

21. I. A. Gill et al, Proc. Biol. Sci, 281. 20132161 (2013).

22. G. Bohrer et al., Data from "Ecological insights from three decades of animal movement tracking across a changing Arctic." Dryad (2020); https://doi.org/10.5061/ dryad. $\mathrm{k} 98 \mathrm{~s}+7 \mathrm{~m} 4 \mathrm{~m}$.

\section{ACKNOWLEDGMENTS}

The findings and conclusions in this article are those of the authors and do not necessarily represent the views of the

U.S. Fish and Wildlife Service, NSF, or NASA. This manuscript has been peer reviewed and approved for publication consistent with USGS Fundamental Science Practices. All tagging studies were performed in accordance with regulations regarding were performed in accordance with regutations rega NNX15AT91A, NNXI5AW71A, NNX15AV92A, NNX15AT89A NNX15AT91A. NNXI5AW71A, NNX15AV92A, NNX15AT89A, NNX15AU20A NSF 1564380, 1823498, 1560727, 185346. 1915347. Funding for studies participating in the AAMA are listed in table S4. Any use of trade, firm, or product names is for descriptive purposes only and does not imply endorsement by the U.S. or Canadian state. province. territory, or federal governments. Author contributions: S.C.D. and G.B. conceived and drafted the manuscript. N.T.B. S.C. . . and G.B. Conceived and drafted the manuscript. N.T.B., agreements. S.C.D. organized and curated the AAMA on Movebank, with assistance from M.W. R.K. produced fig. S2. S.L. E.G., and P.J.M. developed the case studies. M.T.H. L.R.P. J.J. E.G. O.C. A.P.K. A.J.H.M. and R.Y.O. assisted with data interpretation. Other authors (listed alphabetically) contributed data to AAMA. All authors contributed to the writing of the manuscript Competing interests: The authors declare no competing interests. Data and materials availability: Data supporting the analysis in this manuscript are available through Dryad (22). Alaska moose and woll are available through Dryad (22). Alaska moose and woll GPS locations may be made available from K.L. under an
agreement with the National Park Service. Links to studies agreement with the National Park Service. Links to studies access are at www.movebank.org/cms/movebank-content/ arctic-animal-movement-archive.

\section{'Department of Civil, Environmental and Geodetic} Engineering. The Ohio State University, Columbus, OH. USA. ${ }^{2}$ Department of Migration. Max Planck Institute of Animal Behavior, Radolizell, Germany. ${ }^{3}$ Centre for the Advanced Study of Collective Behaviour. University of Konstanz. Konstanz, Germany. 'Department of Biology, University of Maryland, College Park, MD, USA. ${ }^{5}$ Widdife Biology Program. Department of Ecosystem and Conservation Sciences. WA. Franke College of Forestry and Conservation. University of Montana, Missoula, MT. USA. ${ }^{6}$ Black Rock Forest. 65 Reservoir Road, Cornwall, NY. USA. 'Lamont-Doherty Earth Observatory, Columbia University, Palisades, NY, USA.
${ }^{8}$ School of Environmental and Forest Sciences, University of Washington, Seattle. WA, USA. 'Department of Natural Resources and Society, University of Idaho, Moscow. ID. USA ${ }^{10}$ National Socio-Environmental Synthesis Center. Annapolis, MD. USA. "IDepartment of Environment and Annapolis, MD, USA. "Department of Environment and Fatural Resources, Government of the Northwest Territorie Washington State University. Pullman, WA, USA. ${ }^{13}$ Department of Ecology and Evolutionary Biology. Yale University, New Haven, CT. USA. "Wenter for Biodiversity and Global Change, Yale University. New Haven, CT. USA. ${ }^{15}$ College of Natural Resources, North Carolina State University, Raleigh, NC, USA. BoirdLife Nonway, Trondheim, Norway. 1 U.S. Geological Survey. Western Ecological Norway. U.S. Geological Survey, Western Ecological Research Center, Dixon Field Station, Dixon, CA. USA.
${ }^{1 B}$ Department of Biology \& CESAM, University of Aveiro. Aveiro, Portugal. ${ }^{19}$ South Iceland Research Centre, University of Iceland, Laugarvatn. Iceland. ${ }^{20}$ Department of Biological Sciences, University of Alberta, Edmonton. AB, Canada. ${ }^{21}$ Teton Raptor Center, Jackson Hole. WY USA. 22 Global Widdife Conservation Center. College of Environmental Science and Forestry. State University of New York. Syracuse. NY, USA. 23S School of Aquatic \& Fishery Sciences. Unracuse, NY, USA. School of Aquatic \& Fishery University of Washington, Seattie, WA, USA. 24 U.S. Geological Survey. Patuxent Wildlife Research Center. Laurel, MD, USA. ${ }^{25}$ Centre d'études nordiques, Université du Québr
à Rimouski. Rimouski, QC. Canada. 25 Latvian National Museum of Natural History, Riga, Latvia. ${ }^{2}$ Institute of Biology. University of Latvia. Salaspils, Latvia. "Latvian Swan Research Society, Kalnciems, Latvia. ${ }^{2}$ Alaska Department of Fish and Game, Fairbanks. AK, USA. ${ }^{30}$ National Park Service. Denali National Park and Preserve, Denali Park, AK, USA. ${ }^{31}$ Science \& Technology Branch, Environment \& Climate Change Canada, Delta, BC. Canada. ${ }^{32}$ Wildfowl \& Wetlands Trust, Slimbridge, UK. ${ }^{33}$ Manomet, Inc., Saxtons River, VT. USA. ${ }^{34}$ Biological Station Rybachy, Zoological Institute of Russian Academy of Sciences, St. Petersburg. Russia. ${ }^{35} \mathrm{High}$ Arctic Institute, Orion, IL. USA. ${ }^{36}$ School of Biological. Earth and Environmental Sciences, University College Cork, Cork, Ireland. ${ }^{37}$ Alaska Department of Fish and Game. Anchorage. ireland. ${ }^{37}$ Alaska Department of Fish and Game, Anchorage, AK, USA. ${ }^{38}$ Aquila Environmental, Fairbanks, AK. USA ${ }^{\text {Arctic Gull Research Group, Barnfield, BC. Canada. }}$ Government of the Northwest Territories, Inuvik. NT. Canada ${ }^{4}{ }^{4}$ Alaska Department of Fish and Game, Palmer, AK, USA. ${ }^{42}$ Biodiversity Research Institute, Portland, ME, USA. ${ }^{43}$ Reneco International Wildifife Consultants. Abu Dhabi, United Arab Emirates ${ }^{44}$ Raptor View Research Institute. Missoula, MT, USA. ${ }^{45}$ Vogeltrekstation-Dutch Centre for Avian Migration and Demography. Wageningen. Netherlands. ${ }^{46}$ Department of Animal Ecology. Netherlands Institute of Ecology (NIOO-KNAW), Wageningen, Netherlands. ${ }^{47}$ Department of Natural Resource Sciences, McGill University. Ste Anne-de-Bellevue. QC. Canada. ${ }^{48}$ Washington Department of Fish and Wildlife, Olympia, WA, USA. 49 Institute for Avian Research "Vogelwarte Helgoland," Wilhelmshaven, Germany ${ }^{50}$ Fisheries and Oceans Canada. Winnipeg, MB. Canada. "Gi Great Lakes Institute for Environmental Research. School of the Environment. University of Windsor. Windsor. ON. Canada. YLittoral Environnement et Societes (LIENSS), CNRS, La Rochelle Environnement et Societés (LIENSS). CNRS, La Rochelle
University, La Rochelle. France. ${ }^{53}$ Arctic Raptor Project. Rankin Inlet, NU, Canada "Boise State University, Raptor Research Center, Boise, ID, USA. S5Research and Technology Centre (FTZ), Kiel University. Bosum, Germany.

${ }_{56}^{56}$ épartement de Biologie \& Centre d'Etudes Nordiques. Université Laval, Quebec City, QC. Canada. ${ }^{57}$ Environment \& Climate Change Canada, National Wildlife Research Centre. Carleton University, Ottawa, ON. Canada. ${ }^{59}$ Institute of Geography, Russian Academy of Sciences, Moscow. Russia. ${ }^{59}$ School of Biology and Ecology. University of Maine, Orono. ME, USA. ${ }^{60}$ Centre d"Etudes Biologiques de Chizé, CNRS. La Rochelle University. Villiers en Bois. France. ${ }^{61}$ Percy Fitzpatrick Institute of African Ornithology, University of Cape Town, Rondebosch, South Africa. ${ }^{2}$ Migratory Bird Center. Smithsonian Conservation Biology Institute, National Zoological Park. Washington DC. USA. ${ }^{\text {N Northeast Climate }}$ Adaptation Science Center. University of Massachusetts Adaptation Science Center. University of Massachusetts Biology. University of Windsor, Windsor, ON, Canada ${ }_{65}^{65}$ Environment \& Climate Change Canada, Pacific Wildiffe Research Centre, Delta, BC, Canada, ${ }^{66}$ Department of Environment and Natural Resources. Government of the
Northwest Territories, Yellowknife. NT, Canada. ${ }^{67}$ U.S. Fish \& Wildilife Service, Migratory Bird Management, Anchorage, AK, USA, ${ }^{68}$ National Park Service, Gates of the Arctic National Park \& Preserve, Fairbanks, AK. USA. ${ }^{69}$ U.S. Geological Survey, Forest and Rangeland Ecosystem Science Center. Survey, Forest and Rangeland Ecosystem Science Center, Boise, ID, USA.
$7_{\text {institute for Wetlands and Waterbird Research e.V.. Verden }}$ (Aller), Germany. " Department of Integrative Biology. University of Colorado. Denver, CO. USA. ${ }^{73}$ Polar Knowledge Canada, Cambridge Bay. NU. Canada. ${ }^{74}$ Department of Environment and Natural Resources. Government of the Northwest Territories, Fort Simpson, NT. Canada ${ }^{75}$ Manaaki Whenua-Landcare Research, Lincoln. New Zealand. ${ }^{76}$ U.S. Fish \& Widdife Service, Arctic National Wildifife Refuge. Fish \& Widilife Service, Arctic National Widlife Refuge, Inventory and Monitoring Program, Anchorage, AK, USA. Inventory and Monitoring Program, Anchorage, AK, USA.
${ }^{78}$ Korea Institute of Environmental Ecology. Yuseonggu, Daejeon. Republic of Korea. ${ }^{79}$ U.S. Fish \& Wildlife Service. Juneau, AK, USA. ${ }^{80}$ Department of Bioscience-Kalø. Aarhus University, Rønde. Denmark. ${ }^{81}$ Biology Department, Acadia University, Wolfville, NS, Canada. ${ }^{82}$ National Park Service. Lake Clark National Park and Preserve. Anchorage. AK, USA ${ }^{83}$ Department of Biology and the McCourt School of Public. Policy, Georgetown University, Washington, DC, USA. ${ }^{3}$ Wildife Conservation Society. Arctic Beringia Program. Fairbanks, AK, USA ${ }^{85}$ University of Manitoba, Winnipeg, MB, Canada. ${ }^{85}$ Conservation Science Global, Inc. West Cape May, NJ, USA. "Division of Forestry and Natural Resources, West Virginia University. Morgantown, WV. USA. ${ }^{88}$ Department of Ecology and Evolutionary Biology. Princeton University. Princeton. NJ. USA. "Wageningen Environmental Research. Wageningen University \& Research. Wageningen, Netherlands. ${ }^{9}$ Independent researcher. Reykjavik, Iceland. 912aboratory of Omithology. Institute of Biological Problems of the North FEB RAS. Magadan, Russia. ${ }^{92}$ Arctic Research Station of Institute of Plant and Animal Ecology UB, RAS Labytnangi, Yamal-Nenets Autonomous District. Russia. ${ }^{93}$ Durham University, Durham, UK, ${ }^{94}$ University of Glasgow. Glasgow, Scotland. ${ }^{95}$ Marine and Environmental Sciences Centre, Institute of Marine Research and Okeanos R\&D Centre, University of the Azores. Horta, Portugal. ${ }^{96}$ Justus. Liebig University, Gießen. Germany. 97 Environment \& Climate Change Canada, Yellowknife, NT. Canada. Environment Yukon. Whitehorse, YT. Canada. 99 SOVON, Nijmegen, Netherlands. ${ }^{100}$ U.S. Geological Survey Alaska Science Center, Anchorage, AK, USA. ${ }^{101}$ British Columbia Ministry of Environment, Prince George, BC, Canada. ${ }^{102}$ Biology Department. Woods Hole Oceanographic Institution. Woods Hole. MA. USA. 103 U.S. Fish \& Wildlife Service, Migratory Bird Management, Denver, CO. USA. ${ }^{104}$ Center for Conservation Biology. College of William \& Mary. Williamsburg. VA. USA. ${ }^{B 05}$ Georgia Department of Natural Resources, Brunswick, GA. USA. ${ }^{106}$ GawkWatch International, Salt Lake City, UT. USA ${ }^{107}$ H. T. Harvey \& Associates, Los Gatos, CA, USA. ${ }^{108}$ Center for Macroecology. Evolution and Climate, Globe Institute. University of Copenhagen, Copenhagen, Denmark. ${ }_{109}$ Institute of Plant and Animal Ecology. Ural Division Russian Academy of Sciences, Ekaterinburg. Russia. ${ }^{110}$ National Park Service, Yukon-Charley Rivers National Preserve, Central Alaska Inventory and Monitoring Network. Fairbanks, AK. USA. WHawk Mountain Sanctuary. Kempton, PA, USA. "'I2 Wageningen Marine Research, IJmuiden. Netherlands, ${ }^{12}$ Bureau Waardenburg, Culemborg. Netherlands. ${ }^{114}$ Canadian Wildilfe Service, Environment \& Climate Change Canada, Saskatoon, SK. Canada. ${ }^{115}$ North Slope Borough, Department of Wildife Management. Utqiagvik, AK, USA. ${ }^{116}$ School of Environment and Natural Resources, The Ohio State University. Columbus, OH, USA. ${ }^{117}$ Earthspan Foundation. Minden. NV, USA. ${ }^{118}$ Ornitela UAB, Vilnius, Lithuania. 